
$\$$ Research Square
Preprints are preliminary reports that have not undergone peer review.
They should not be considered conclusive, used to inform clinical practice, or referenced by the media as validated information.

\title{
Factors affecting perioperative serum albumin variation and short term complications in pediatric patients undergoing major gastroenterology surgery
}

\section{Qingshuang Liu}

Chongqing Medical University Affiliated Children's Hospital

\section{Kai Gao}

Chongqing Medical University Affiliated Children's Hospital

\section{Xiaomin Sun}

Chongqing Medical University Affiliated Children's Hospital

Chunbao Guo ( $\nabla$ guochunbao@foxmail.com )

Chongqing Medical University https://orcid.org/0000-0002-9132-3096

Research article

Keywords: $\triangle$ ALB, Roux-en-Y hepaticojejunostomy, Postoperative recovery, Perioperative complications

Posted Date: May 11th, 2020

DOI: https://doi.org/10.21203/rs.2.24434/v2

License: (c) (i) This work is licensed under a Creative Commons Attribution 4.0 International License. Read Full License 


\section{Abstract}

Background: Albumin is considered a negative acute-phase protein because its concentration decreases during injury and sepsis. The decrease in serum albumin might be important for perioperative morbidity, even in patients with normal preoperative levels in pediatric population. We here intend to determine the perioperative factors associated with the reduction in serum albumin within 2 postoperative days compared with the preoperative level $(\triangle \mathrm{ALB})$ and its influence on the perioperative outcome in a pediatric general surgical cohort.

Methods: This single-center retrospective review included 939 patients who underwent Roux-en-Y hepaticojejunostomy between August 2010 and Aug 2019. Based on the mean valure of $\triangle$ ALB (14.6\%), patients were separated into two groups, including a high $\triangle$ ALB group $(\geq 14.6 \%)$ and a low $\triangle$ ALB group $(<14.6 \%)$. Multivariable logistic regression analyses were performed to determine the independent risk factors for the reduction in serum albumin. Propensity score matching was performed to adjust for any potential selection bios for the two groups. In 366 matched patients, influences of operating time on perioperative outcomes, including postoperative recovery, complications measurement, and length of hospital stay between the two groups were analyzed.

Results: For all 996 patients reviewed, 939 patient records were enrolled into the final analysis. Controlling for other factors, multivariate analysis showed that the high CRP on POD 3 or 4 (odds ratio[OR] $=2.36$ [95\% Cl, 1.51-3.86]; $p=0.007)$, presence of Charcot's triad ( $\mathrm{OR}=1.73[95 \% \mathrm{Cl}, 1.05-2.83] ; p=0.031)$, the longer operating time $(\mathrm{OR}=1.18[95 \% \mathrm{Cl}, 1.00-1.53] ; \mathrm{p}=0.014)$ were factors that predicted the high $\triangle \mathrm{ALB}$ level. The high $\triangle A L B$ level was associated with postoperative gastrointestinal functional recovery, reflected by the first defecation $(p=0.013)$ and first bowel movement $(p=0.019)$ and the high occurrence of postoperative complications ( $16.1 \%$ vs $10.9 \%$, OR, $1.57 ; 95 \% \mathrm{Cl}, 1.02-2.41, \mathrm{P}=0.0026)$. The mean length of postoperative stay was longer than that of patients with $\triangle A L B<14.0 \%$ group, although no statistic significant was stained $(p=0.057)$.

Conclusions: We showed that change in albumins was associated with postoperative outcomes. The risk factors for $\triangle A L B$ could be intervened in the perioperative period to permit patients gain a safe recovery and discharge after major abdominal operations.

\section{Background}

As a acute-phase protein, albumin (ALB) is usually negatively response to surgical stress, injury or sepsis, etc $[1,2]$. The decrease of plasma albumin concentration is considered one of the features of the systemic inflammatory, due to loss of albumin to the tissue spaces $[3,4]$ and so be considered as acutephase protein to predict the postoperative infectious complication [4]. The preoperative hypoalbuminemia was also confirmed as an indicator for mortality and postoperative complications and poor nutritional status, like surgical site infections (SSI) after spine surgery [5], GI surgery [6], acute kidney injury after living donor liver transplantation[7], which prolonged intensive care unit stays and inpatient stay. Because 
albumin has quick kinetics after surgery, the response of albumin to surgical stress even occur earlier than CRP, so has been focused intensively during perioperative management $[8,9]$.

An sharp decrease by $33 \%$ of serum ALB within 2 days was observed after major abdominal surgery, which occurred earlier than the another acute-phase protein, CRP[2, 10]. The transcapillary leakage of albumin could elevated more than $300 \%$ in the systemic inflammatory pathogenesis $[11,12]$. There are many factors that may potentially impact upon the reduction of ALB level $(\triangle A L B)$ including the pathology being treated, and the actual procedure undertaken, which is common among all types of surgical approaches [13]. Few studies have examined which factors could be used to predict future hypoalbuminemia in pediatric patients in the perioperative period of major gastroenterology surgery. A clear evaluation these factors might optimize the perioperative care protocol in regard to serum ALB. Furthermore, although the $\triangle A L B$ had been evaluated previously, especially in adult patients, the $\triangle A L B$ level remains poorly defined for practice among pediatric patients.

This study aimed to investigate the risk factors for reduction of ALB by retrospectively reviewing data on pediatric patients undergone major gastroenterological surgery. We further sought to clarify the association between $\triangle \mathrm{ALB}$ and postoperative recovery and outcomes and its diagnostic accuracy.

\section{Methods}

Population selection

The Ethics Committee of the Chongqing Medical University gave expedited approval of this protocol. This retrospective study included 996 consecutive patients who underwent elective Roux-en-Y hepaticojejunostomy between August 2010 and Aug 2019 at the department of general surgery of the affiliated chongqing children's Hospital, Chongqing medical university. Exclusion criteria included patients with ALB infusion preoperatively or within postoperative day (POD 1), or incomplete laboratory data.

\section{Data collection and definitions}

Electronic medical records upon admission or referral and included clinician and nurse notes, laboratory tests, imaging exams, surgical records and histopathology results were individually reviewed and collected by two well trained clinical investigators who collected the relevant data. Data extraction included three aspects: (1) Preoperative data, including demographic data, clinical details, like preoperative neutrophils, lymphocytes, hemoglobin, preoperative CRP and ALB, and pre-existing comorbidities; (2) Intraoperative variables, including surgical procedures (surgical approach, type of resection), American Society of Anesthesiology (ASA) classification, operation time, duration of operation, estimated blood loss (EBL), intraoperative blood transfusion, intraoperative hemoglobin levels; (3) The postoperative outcomes, included CRP on POD 3 or 4, ALB on POD 1, the prompt postoperative biochemical profiles (hemoglobin, blood glucose, creatinine, serum electrolytes, albumin, retinol binding protein, WBC, CRP, etc), gastrointestinal function recovery features and postoperative complications. The following laboratory data were determined preoperatively and on PODs 3 and 7: serum albumin, CRP, aspartate aminotransferase (AST), alanine aminotransferase (ALT), gamma-glutamyl transpeptidase ( ${ }^{-}$ 
GTP), lactate dehydrogenase (LDH), alkaline phosphatase (ALP), serum creatinine (Scr), blood urea nitrogen (BUN), hemoglobin ( $\mathrm{Hb})$, and white blood cell (WBC) count. Gastrointestinal symptoms were recorded for the first 5 days postoperatively, including the first postoperative flatus or defecation, gastric retention, nausea or vomiting, time to normal diet, abdominal bloating and/or cramps. All postoperative complications were recorded and ranked according to the Clavien-Dindo classification system[14], such as postoperative hemorrhage, anastomotic fistula, anastomotic stenosis and wound infection, intraabdominal abscesses, pneumonia, bacteremia, renal failure and respiratory failure, and so on.

Relative change of the serum albumin ( $\triangle \mathrm{ALB}$ ) was calculated as follows: (preoperative albumin level nadir albumin level within POD 2)/albumin level before surgery $\times 100 \%$ [17]. We have evaluated the $\Delta$ ALB as normally distributed data and decided to use the mean value of $\triangle$ ALB $(14.6 \%)$ to dichotomize groups. For the purposes of analysis, the patients were dichotomized into low $(<14.6 \%)$ and high $(\geq 14.6 \%)$ groups based on the cutoff value (14.6\%).

According to criteria reported in previous studies, all patient data were reviewed for postoperative surgical and nonsurgical outcomes, including complication rates, complication types, mortality rates, ventilator rates, ICU-stay rates, and total lengths of hospital stay (the number of days from the day of operation until the date of discharge). The primary outcome based on $\triangle$ ALB was the prompt postoperative gastrointestinal function recovery. The secondary outcomes were the postoperative complications, and the immunologic and inflammatory variables. Gastrointestinal symptoms were assessed and recorded daily for the first 5 days postoperatively, including first bowel movement (gas and feces) after operation, abdominal bloating, abdominal cramps, diarrhea (defined as more than three bowel movements per day), and vomiting. Wound complications consisted of wound dehiscence, erythema, swelling, and pus.

Propensity scores and matching

To minimize the selection biases in baseline characteristics between the two groups, propensity score matching was accomplished using a multivariable logistic regression model using SPSS 20.0 (IBM, Armonk, NY) or R 3.1.2 (The R Foundation for Statistical Computing). A 1:1 Propensity scores matching with a caliper distance of 0.2 without replacement, was accomplished using nearest-neighbor analysis, which included the demographic and clinical variables. The selected variables entered into the propensity model were based on theoretical and empirical considerations according to the scientific literature and biological plausibility, including demographic data information, laboratory values, treatment protocols, surgical feature, etc. We further measured the interaction among all pre-test covariates. The linear assumption was checked using the generalized additive model. The generalized additive model was used to check linear assumption in PS model, thus matching 366 patients with high $\triangle \mathrm{ALB} \geq 14.6 \%$ and 366 patients with $\triangle A L B<14.6 \%$. The perioperative outcomes between the two groups were compared after propensity score matching.

Statistical analysis 
Statistical analyses were performed using SPSS version 19.0 (SPSS Inc., Chicago, IL, United States). Categorical data were expressed as counts with percentages and were analyzed using the Fisher's exact test or Pearson's $\chi 2$ test when appropriate. Continuous data were expressed as the means \pm (standard deviations) for normally distributed data and medians (interquartile ranges) for non-normally distributed data, which were tested with the Student's t-test or Mann-Whitney $U$ test and the Wilcoxon rank-sum test, respectively. To verify independent predictors for postoperative complications, multivariate analysis was performed using multivariate logistic regression analysis after univariate analysis to identify those with a significance level of $\mathrm{P}<0.30$ (Table 3 ). The results of the multivariate logistic regression analysis were expressed using $P$ value, odds ratio (OR), and 95\% confidence interval (CI). The SPSS 20.0 (IBM, Armonk, NY, USA) software was used to perform all statistical analyses. In all cases, $P<0.05$ was considered significant.

\section{Results}

\section{Patient population characteristics}

Among the initial 996 pediatric patients in our department underwent hepatico-jejunostomy resection, 41 of them did not fulfill inclusion criteria and were initially excluded, sixteen patients were excluded because notes were unobtainable for data extraction. Finally, A total of 939 patient records were enrolled into the final analysis (Table 1).

\section{The factors associated with $\triangle \mathrm{ALB}$}

Based on the cutoff value of $\triangle A L B$, we dichotomized the patients into two groups, the $\triangle A L B \geq 14.6 \%$ and $\triangle A L B<14.6 \%$ group. The baseline features of the two groups are summarized in Table 1 . There were no significant differences in the demographic features of patients, ASA classification, preoperative CRP between the two groups (Table 1). Furthermore, the nadir of hemoglobin and operative blood loss was similar between the two groups $(P>0.05)$. A lager choledochal cyst size $(p=0.042)$, and worse comorbidity (Charcot's triad) ( $p=0.011)$, lower preoperative ALB $(p=0.016)$, CRP on POD 3 or $4(p<0.001)$, and long surgery duration $(p=0.0024)$, were often associated with a greater $\triangle A L B(P<0.05)$ in the univariate analysis. Multivariate analysis revealed three independent risk factors. As shown in Table 2, the CRP on POD 3 or $4(\mathrm{OR}=2.36[95 \% \mathrm{Cl}, 1.51-3.86] ; \mathrm{p}=0.007)$, presence of Charcot's triad (OR $=$ $1.73[95 \% \mathrm{Cl}, 1.05-2.83] ; p=0.031)$, the longer operating time $(\mathrm{OR}=1.18[95 \% \mathrm{Cl}, 1.00-1.53] ; p=0.014)$ were the independent risk factors associated with $\triangle \mathrm{ALB}$.

The influences of $\triangle A L B$ on postoperative outcomes

To explore the association of $\triangle A L B$ and the perioperative outcomes, we performed PS-matching between the patients with the $\triangle A L B \geq 14.6 \%$ and $\triangle A L B<14.6 \%$ groups to adjust for potential confounding factors 
and exclude the effects of correlation between factors. Under PS-matching, 366 patients with $\triangle A L B \geq$ $14.6 \%$ group were matched to 366 patients with $\triangle A L B<14.6 \%$ group. The absolute standardized mean differences reduced the values, indicating that the continuous and categorical variables were very similar and comparable between the two groups (Table 3).

Overall, there were no differences in the vasopressor support, diuresis usage and the number of intraoperative hypotensive events, hypokalemic episodes, metabolic acidosis (defined by low bicarbonate) or other laboratory and hemodynamic parameters throughout the perioperative period between the $\triangle A L B \geq 14.6 \%$ and $\triangle A L B<14.6 \%$ groups (Table 4 ).

In the propensity matched cohort, patients with $\triangle \mathrm{ALB}<14.6 \%$ had reduced the time for first flatus $(p=0.013)$ and first bowel movement $(p=0.019)$ (Table 4$)$. In the $\Delta A L B<14.6 \%$ group, $40.2 \%(147 / 366)$ of patients spontaneously passed stool within 72 hours, whereas only $33.6 \%(123 / 366)$ cases in the high urine output passed stool within the same period $(\mathrm{OR}, 1.33 ; 95 \% \mathrm{Cl}, 0.98-1.79, \mathrm{p}=0.039)$. The incidences of Diarrhea $(p=0.50)$, Vomiting $(p=0.38)$ and abdominal distention $(p=0.18)$ within 5 PODs in patients with $\triangle \mathrm{ALB}<14.6 \%$ were similar with patients with $\triangle \mathrm{ALB} \geq 14.6 \%$.

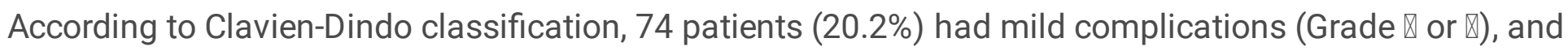
$49(13.4 \%)$ had major complications (Grade III or greater). As shown in Table 4, patients with $\triangle$ ALB $\geq$ $14.0 \%$ were found to have more total complications than those with $\triangle \mathrm{ALB}<14.0 \%(16.1 \%$ vs $10.9 \%$, OR, $1.57 ; 95 \% \mathrm{Cl}, 1.02-2.41, \mathrm{P}=0.0026)$, including anastomotic leakage, infectious complications of pneumonia, incision dehiscence, intraperitoneal abscess, sepsis, and surgical site infections, etc. In addition, The mean length of postoperative stay was $8.19 \pm 3.16$ days in patients with $\triangle A L B \geq 14.0 \%$ group, which was longer than that of patients with $\triangle A L B<14.0 \%$ group $(7.69 \pm 2.67$ days), although no statistic significant was stained $(p=0.057)$.

\section{Discussion}

We conducted the present analysis to focus on serum albumin as an acute phase protein for a pediatric surgical cohort following the same surgical procedure. This study revealed that several factors were associated with the high $\triangle A L B$, like the operative duration, disease comorbidities, the mean CBD, etc. Furthermore, patients with a greater relative decrease in serum albumin were associated with postoperative gastrointestinal function recovery, postoperative complications, prolonged postoperative hospital stay.

The factors led to hypoalbuminemia were often complicated and involved in operative case type, ALB loss, redistribution, catabolism, and so on $[15,17,18]$. In patients with sepsis and surgical trauma, systemic inflammatory response is recognized as a common reason for albumin fractional synthesis rate (FSR) and capillary leakage increase, whereas the absolute synthesis rates (ASRs) was unaltered, which account for the reduction in ALB level $[11,2,16]$. Numerous studies have focused the preoperative and postoperative hypoalbuminemia as risk factors for postorepative complications [5, 19], while few have specifically stressed the perioperative factors related to the $\triangle A L B$, which may be clinically significant for 
postoperative care. In present study, several clinical factors related to the decrease in postoperative albumin were presented, including longer operating time, severe comorbidities, like Charcot's triad, and high CRP, etc. All these factors might be associated with an inflammatory response caused by surgical stress. During surgery, manipulation of the intestine is proved to initiate the gastrointestinal edema [20, 21]. The postoperative edema might attribute to the low colloid osmotic pressure and fluid accumulation, which resulted from the low postoperative $\triangle$ ALB level [11]. Consistent with the current findings, previous reports focused primarily on adult patients with various co-morbidities, higher ASA scores, and a wide variety of serious conditions, ranging from major trauma to extensive pancreatic surgery. Norberg $\AA[2]$ reported the stress response led to a reduction in postoperative albumin levels, which was consistent with the findings in our study.

Changes in plasma volume and altered distribution between the intravascular and extravascular space also play a significant role for the plasma albumin concentrations. The intraoperative and postoperative fluid use, which has not been shown in previous studies to be associated with high $\triangle$ ALB after Roux-en-Y hepaticojejunostomy. The reasons for this association may pertain to hemodilution, which might contribute to the decreased albumin level after surgery. In my previous study [22], postoperative complications were related to conventional intraoperative and postoperative fluid usage, it might also affect the albumin level after surgery. The excessive fluid should also promote capillary permeability and leakage of serum albumin into the extravascular space [23]. Capillary leakage is especially common in some malnourished patients with surgical trauma followed by an increased transcapillary escape rate of $\geq 100 \%$ [24], which was not presented in the current research. Serum albumin on POD 3 was observed to be correlated with preoperative CRP level $[13,25]$. In the current research, we indeed found that high $\triangle \mathrm{ALB}$ was associated with the CRP on POD 3 or 4.

Prompt postoperative recovery serves as the main focus of all surgical specialties for the postoperative rehabilitation [26]. As indicated in the current study, although uneventful recovery was presented in most patients following choledochal cyst resection, the unfavorable postoperative gastroenterological recovery was associated with the high $\triangle \mathrm{ALB}$. In previous biological investigation, it have demonstrated that edema's detrimental effects on intestinal function by directly affecting muscle function and force transmission[27, 28]. The serum ALB is a predictor of both systemic inflammation and nutritional status, which should account for postoperative intestine edema after major operation or severe trauma. Furthermore, tissue oxygenation might decline with fluid accumulation, also unfavorable for the postoperative recovery and complications. In this study, we detected an increased total number of complications, including anastomotic leakage, in patients with high $\triangle A L B$. The possible explanation at the tissue level indicated that the low ALB level decline the collagen deposition for the tissue connections and, therefore, poor structural integrity. The effect of $\triangle A L B$ on local inflammatory response and edema recovery is also important, which might also explain the postoperative recovery and complications[29, 30]. Exogenous ALB supplementation strategy has been proposed as the optimal therapeutic modality to attenuate the postoperative intestine edema after major operation or severe trauma. However, others reported that routine ALB infusion was not beneficial to patients in the European intensive care units (ICUs)[31]. Instead, exogenous ALB administration might increase risks of edema, 
extravasation of albumin, or other postoperative complications[32]. It remains to be established whether ALB supplementation would reduce the postoperative intestine edema and cellular swelling so to benefit patients and promote intestinal function recovery in patients undergoing major upper gastrointestinal surgery in pediatric population.

There were several limitations to the current study. First, it was a retrospective observational analysis, where unmeasured differences, known selection and treatment bias may contribute to confounding, which could not be entirely excluded. Second, it was a single-center study and the general surgery procedures were performed in our hospital over a long period of time; therefore, there may have been many practice changes within both surgical and the ICU divisions, leading to different care practices between study patients, which may not reflect the outcomes from current treatment algorithms. Another point of emphasisis was that although we did not find differences in baseline characteristics after PS matching, the patients with high $\triangle \mathrm{ALB}$ might have been more surgically challenged than the low $\triangle \mathrm{ALB}$. To limit the influence of confounding variables on the actual effects of $\triangle A L B$, large, multicenter prospective studies must be performed to verify the conclusions of the current study.

\section{Conclusions}

In the current study, we have characterized some risk factors that may predispose to high $\triangle A L B$, which impacts negatively on the postoperative recovery after pediatric major abdominal operation. The surgeons should be aware of the $\triangle \mathrm{ALB}$ variation in the early postoperative period to optimize preoperative planning and maximize surgical efficiency.

\section{Abbreviations}

ALB: albumin;

ALP: alkaline phosphatase;

ALT: alanine aminotransferase;

$\triangle \mathrm{ALB}$ : reduction of ALB level;

ASA: American Society of Anesthesiology;

AST: aspartate aminotransferase;

BUN: blood urea nitrogen;

CBD: Common bile duct;

Cl: confidence interval;

CRP: C-reactive protein; 
Y-GTP: gamma-glutamyl transpeptidase;

$\mathrm{Hb}$ : hemoglobin

LDH: lactate dehydrogenase;

OR: odds ratio;

POD: postoperative day;

Scr: serum creatinine;

SD: standard deviation;

WBC: white blood cell.

\section{Declarations}

* Ethics approval and consent to participate

Not required.

* Consent for publication

Our manuscript does not contain any identifiable individual's data in any form (including individual details, images or videos). That the article is original, has not already been published in a journal, and is not currently under consideration by another journal.

* Availability of data and material

The dataset analyzed during the current study are available from the corresponding author on reasonable request.

* Competing interests

No potential conflicts of interest relevant to this article are reported.

* Funding

This study was supported by grants from the National Natural Science Foundation of China (Nos: 30973440 and 30770950) in the design of the study, the Key Project of the Chongqing Natural Science Foundation (CSTC, 2008BA0021, cstc2012jjA0155) for collection, analysis, and interpretation of data and the Chongqing Health Planning Commission of Research Fund (No: 2016MSXM044) in writing the manuscript.

* Authors' contributions

QL, KG and XS designed the study and analyzed the data. KG, XS and CG evaluated the manuscript. CG and KG performed the statistical measurements and analyzed the data. CG analyzed the data and wrote 
the paper. All authors have read and approved the final manuscript as submitted and agree to be accountable for all aspects of the work.

* Acknowledgements

We thank Prof. Bailin Chen for providing technical assistance and for insightful discussions during the preparation of the manuscript and Dr Xiaoyong Zhang at the Wistar Institute for help with the linguistic revision of the manuscript.

* Authors' information (optional)

Correspondence to Xiaomin Sun or Chunbao Guo.

\section{References}

1.Wierdak M, Pisarska M, Kuśnierz-Cabala B, Witowski J, Dworak J, Major P, Małczak P, Ceranowicz P, Budzyński A, Pędziwiatr M. Changes in plasma albumin levels in early detection of infectious complications after laparoscopic colorectal cancer surgery with ERAS protocol. Surg Endosc. 2018 Jul;32(7):3225-3233.

2.Norberg Å, Rooyackers O, Segersvärd R, Wernerman J. Albumin Kinetics in Patients Undergoing Major Abdominal Surgery. PLoS One. 2015 Aug 27;10(8):e0136371.

3. Norberg Å, Rooyackers O, Segersvärd R, Wernerman J. Leakage of albumin in major abdominal surgery. Crit Care. 2016 Apr 26;20(1):113.

4.Migita K, Matsumoto S, Wakatsuki K, Kunishige T, Nakade H, Miyao S, Sho M. Postoperative Serum CReactive Protein Level Predicts Long-term Outcomes in Stage I Gastric Cancer. J Surg Res. 2019 Oct;242:323-331.

5.Adogwa O, Martin JR, Huang K, Verla T, Fatemi P, Thompson P, Cheng J, Kuchibhatla M, Lad SP, Bagley CA, Gottfried ON. Preoperative serum albumin level as a predictor of postoperative complication after spine fusion. Spine (Phila Pa 1976). 2014 Aug 15;39(18):1513-9.

6.Rudasill SE, Morales RR, Sanaiha Y, Sareh S, Antonios JW, Khoury H, Mardock AL, Benharash P. Predicting morbidity and mortality in laparoscopic cholecystectomy: Preoperative serum albumin still matters. Am J Surg. 2019 Dec 6. pii: S0002-9610(19)31556-9.

7.Cabezuelo JB, Ramírez P, Ríos A, Acosta F, Torres D, Sansano T, Pons JA, Bru M, Montoya M, Bueno FS, Robles R, Parrilla P. Risk factors of acute renal failure after liver transplantation. Kidney Int. 2006 Mar;69(6):1073-80.

8.Amouzandeh M, Nowak G, Januszkiewicz A, Wernerman J, Rooyackers O, Norberg Å. Albumin mass balance and kinetics in liver transplantation. Crit Care. 2018 Jun 7;22(1):152. 
9.Komáromi A, Estenberg U, Hammarqvist F, Rooyackers O, Wernerman J, Norberg Å. Simultaneous assessment of the synthesis rate and transcapillary escape rate of albumin in inflammation and surgery. Crit Care. 2016 Nov 15;20(1):370.

10. Dumitrescu G, Komaromi A, Rooyackers O, Klaude M, Hebert C, Wernerman J, Norberg Å. Repeated quantitative measurements of De Novo synthesis of albumin and fibrinogen. PLoS One. 2017 Mar 28;12(3):e0174611.

11.Fleck A, Raines G, Hawker F, Trotter J, Wallace PI, Ledingham IM, Calman KC. Increased vascular permeability: a major cause of hypoalbuminaemia in disease and injury. Lancet. 1985;1:781-4.

12. Nicholson JP, Wolmarans MR, Park GR. The role of albumin in critical illness. Br J Anaesth. 2000;85:599-610.

13.Sonoda A, Ohnishi S, Nakao S, Iwashita Y, Hashimoto N, Ishida K, Kondo Y, Ishitsuka Y, Irie T. Factors affecting serum albumin in the perioperative period of colorectal surgery: a retrospective study. BMC Res Notes. 2015 Nov 3;8:638.

14. Dindo D, Demartines N, Clavien PA. Classification of surgical complications: a new proposal with evaluation in a cohort of 6336 patients and results of a survey. Ann Surg. 2004 Aug; 240(2):205-13

15. Norberg $\AA$, Rooyackers O, Segersvärd R, Wernerman J. Albumin kinetics in patients undergoing major abdominal surgery. PLoS One. 2015;10:e0136371.

16.Ruot B, Papet I, Bechereau F, Denis P, Buffiere C, Gimonet J, Glomot F, Elyousfi M, Breuille D, Obled C. Increased albumin plasma efflux contributes to hypoalbuminemia only during early phase of sepsis in rats. Am J Physiol Regul Integr Comp Physiol. 2003 Mar;284(3):R707-13.

17.Giovannini I, Chiarla C, Giuliante F, Vellone M, Ardito F, Nuzzo G. The relationship between albumin, other plasma proteins and variables, and age in the acute phase response after liver resection in man. Amino Acids. 2006 Nov;31(4):463-9.

18.Labgaa I, Joliat GR, Kefleyesus A, Mantziari S, Schäfer M, Demartines N, Hübner M. Is postoperative decrease of serum albumin an early predictor of complications after major abdominal surgery? A prospective cohort study in a European centre. BMJ Open. 2017 Apr 8;7(4):e013966.

19.Labgaa I, Joliat GR, Demartines N, Hübner M. Serum albumin is an early predictor of complications after liver surgery. Dig Liver Dis. 2016 May;48(5):559-561.

20. Boelens PG, Heesakkers FF, Luyer MD, et al. Reduction of postoperative ileus by early enteral nutrition in patients undergoing major rectal surgery: prospective, randomized, controlled trial. Ann Surg. 2014;259:649-655. 
21. Ozacmak HS, Ozacmak VH, Barut F, et al. Pretreatment with mineralocorticoid receptor blocker reduces intestinal injury induced by ischemia and reperfusion: involvement of inhibition of inflammatory response, oxidative stress, nuclear factor $\mathrm{kB}$, and inducible nitric oxide synthase. $\mathrm{J}$ Surg Res. 2014;191:350-361.

22.Tan X, Liu J, Guo C. Crystalloid Administration Is Associated with the Recovery of Pediatric Elective Roux-en-Y Hepaticojejunostomy. Eur J Pediatr Surg. 2019 Jan 21. doi: 10.1055/s-0038-1677544. [Epub ahead of print]

23.Nicholson JP, Wolmarans MR, Park GR. The role of albumin in critical illness. Br J Anaesth. 2000;85:599-610.

24.Lee WL, Slutsky AS. Sepsis and endothelial permeability. N Engl J Med 2010; 363: 689-691

25.Bona D, Micheletto G, Bonitta G, Panizzo V, Cavalli M, Rausa E, Cirri S, Aiolfi A. Does C-reactive Protein Have a Predictive Role in the Early Diagnosis of Postoperative Complications After Bariatric Surgery? Systematic Review and Bayesian Meta-analysis. Obes Surg. 2019 Nov;29(11):3448-3456.

26. Hao F, Guo H, Zhong J, Geng Q, Yang Y, Chen B, Guo C. Effects of Prostaglandin E1 on Patients Undergoing Major Gastrointestinal Surgery. Ann Surg. 2018 Apr;267(4):759-765.

27. Kinsky MP, Milner SM, Button B, et al. Resuscitation of severe thermal injury with hypertonic saline dextran: effects on peripheral and visceral edema in sheep. J Trauma. 2000;49:844-53.

28. Luiz Zanoni F, Costa Cruz JW, et al. Hypertonic saline solution reduces mesenteric microcirculatory dysfunctions and bacterial translocation in a rat model of strangulated small bowel obstruction. Shock. 2013;40:35-44.

29.Rasslan R, Utiyama EM, Marques GM, et al. Inflammatory activity modulation by hypertonic saline and pentoxifylline in a rat model of strangulated closed loop small bowel obstruction. Int J Surg. 2014;12:594600 .

30.Vincent JL, De Backer D, Wiedermann CJ. Fluid management in sepsis: The potential beneficial effects of albumin. J Crit Care. 2016 Oct;35:161-7

31. Vincent JL, Sakr Y, Reinhart K, Sprung CL, Gerlach H, Ranieri VM; 'Sepsis Occurrence in Acutely III Patients' Investigators. Is albumin administration in the acutely ill associated with increased mortality? Results of the SOAP study. Crit Care. 2005;9(6):R745-54.

32. Margarson MP, Soni N. Serum albumin: touchstone or totem? Anaesthesia. 1998;53:789-803.

\section{Tables}

Table 1. Univariate analyses of perioperative factors associated with $\Delta$ ALB 


\begin{tabular}{|c|c|c|c|}
\hline & \multicolumn{3}{|l|}{ Total Population } \\
\hline & $\Delta \mathrm{ALB} \geq 14.6 \%(471)$ & $\Delta \mathrm{ALB}<14.6 \%(468)$ & $\mathrm{p}$ Values \\
\hline Age $(y r s)$, mean \pm SD & $2.13 \pm 1.02$ & $2.16 \pm 1.07$ & 0.21 \\
\hline Female: Male & 183(37.5) & $191(39.9)$ & 0.31 \\
\hline Weight $(\mathrm{kg})$, mean $\pm \mathrm{SD}$ & $11.38 \pm 2.96$ & $11.52 \pm 3.68$ & 0.22 \\
\hline BMI, median (range) & $24(20-30)$ & $25(21-31)$ & 0.13 \\
\hline \multicolumn{4}{|l|}{ Laboratory findings } \\
\hline hypertransaminasemia, n (\%) & $325(69.0)$ & $334(71.4)$ & 0.47 \\
\hline hyperbilirubinemia, n (\%) & 186(39.5) & $173(37.0)$ & 0.39 \\
\hline Preoperative $\mathrm{ALB}(\mathrm{g} / \mathrm{L})$, mean $\pm \mathrm{SD}$ & $39.28 \pm 4.72$ & $41.41 \pm 5.39$ & 0.016 \\
\hline Preoperative $\mathrm{CRP}(\mathrm{g} / \mathrm{L})$, mean $\pm \mathrm{SD}$ & $11.24 \pm 3.26$ & $12.56 \pm 4.17$ & 0.15 \\
\hline Preoperative WBC $(109 / \mathrm{L})$, mean \pm SD & $7.9 \pm 2.8$ & $8.2 \pm 3.1$ & 0.52 \\
\hline \multicolumn{4}{|l|}{ Ultrasound presentation } \\
\hline Mean $\mathrm{CBD}(\mathrm{cm})$, mean $\pm \mathrm{SD}$ & $1.53 \pm 0.58$ & $2.34 \pm 0.97$ & 0.042 \\
\hline Charcot's triad, n (\%) & $142(30.1)$ & $109(23.3)$ & 0.011 \\
\hline Nadir ALB within POD 2(g/L), mean \pm SD & $34.94 \pm 8.92$ & $30.22 \pm 7.83$ & 0.0012 \\
\hline CRP on POD 3 or $4(\mathrm{mg} / \mathrm{L})$, mean $\pm \mathrm{SD}$ & $41.45 \pm 13.65$ & $29.8 \pm 7.69$ & $<0.001$ \\
\hline Postoperative WBC(109/L), mean \pm SD & $15.8 \pm 4.9$ & $14.9 \pm 4.8$ & 0.350 \\
\hline \multicolumn{4}{|l|}{ Mode of surgical approach, $\mathrm{n}(\%)$} \\
\hline Laparoscopic & $168(35.7)$ & $139(29.7)$ & \\
\hline Open & $303(64.3)$ & $329(70.3)$ & 0.03 \\
\hline Operation time, median (range), min & $175(132-418)$ & $143(115-367)$ & 0.0024 \\
\hline Nadir of hemoglobin(g/L) & $9.18 \pm 1.32$ & $9.64 \pm 1.68$ & 0.28 \\
\hline Operative blood loss $(\mathrm{mL})$, mean $\pm \mathrm{SD}$ & $36.78 \pm 16.84$ & $33.86 \pm 15.88$ & 0.26 \\
\hline Intraoperative fluid utilization $(\mathrm{mL} / \mathrm{kg} * \mathrm{~h})$, mean $\pm \mathrm{SD}$ & $16.74 \pm 6.88$ & $14.26 \pm 6.72$ & 0.017 \\
\hline Intraoperative transfusion, $\mathrm{n}(\%)$ & $131(27.8)$ & $115(24.6)$ & 0.15 \\
\hline \multicolumn{4}{|l|}{ ASA classification } \\
\hline ASA $1-2$ & $338(72.6)$ & $319(67.7)$ & 0.13 \\
\hline ASA3-4 & $133(27.4)$ & $149(22.3)$ & \\
\hline
\end{tabular}

Abbreviations:ALB, albumin; $\triangle \mathrm{ALB}$, reduction of ALB level; ASA, American Society of Anesthesiology; CBD, Common bile duct; CRP, Creactive protein; POD, postoperative day; SD, standard deviation; WBC, white blood cell. 
Table 2. Multivariate analysis of perioperative factors associated with $\triangle \mathrm{ALB}$.

\begin{tabular}{l|l|l|l|}
\hline & OR & $95 \% \mathrm{Cl}$ & $\mathrm{p}$ \\
\hline BMI>26 & 1.26 & $(0.97-1.89)$ & 0.16 \\
\hline Preoperative ALB<32g/L & 1.68 & $(0.91-2.35)$ & 0.27 \\
\hline Preoperative CRP $>12 \mathrm{~g} / \mathrm{L}$ & 1.12 & $(0.94-1.73)$ & 0.18 \\
\hline CRP on POD 3 or 4 (>135mg/L) & 2.36 & $(1.51-3.86)$ & 0.007 \\
\hline Charcot's triad & 1.73 & $(1.05-2.83)$ & 0.031 \\
\hline Operation time(>165m) & 1.18 & $(1.01-1.53)$ & 0.014 \\
\hline Open surgical approach & 2.31 & $(0.89-4.76)$ & 0.31 \\
\hline Intraoperative fluid utilization>17mL/kg*h & 1.07 & $(0.96-1.78)$ & 0.22 \\
\hline Intraoperative transfusion & 1.38 & $(0.98-2.16)$ & 0.092 \\
\hline ASA classification(ASA1-2) & 1.74 & $(0.96-3.24)$ & 0.39 \\
\hline
\end{tabular}

Table 3. The inclusion variables in the PS-matching analysis 


\begin{tabular}{|c|c|c|c|}
\hline & \multicolumn{3}{|l|}{ Total Population } \\
\hline & $\Delta \mathrm{ALB} \geq 14.6 \%(366)$ & $\Delta \mathrm{ALB}<14.6 \%(366)$ & $\mathrm{p}$ Values \\
\hline Age (yrs) & $2.14 \pm 1.01$ & $2.15 \pm 1.03$ & 0.45 \\
\hline Female: Male & $135(36.9)$ & $136(37.2)$ & 0.50 \\
\hline Weight (kg) & $11.44 \pm 2.76$ & $11.46 \pm 3.11$ & 0.34 \\
\hline BMI, median (range) & $25(21-28)$ & $25(21-29)$ & 0.28 \\
\hline \multicolumn{4}{|l|}{ Laboratory findings } \\
\hline hypertransaminasemia, n (\%) & $252(68.9)$ & $251(68.6)$ & 0.50 \\
\hline hyperbilirubinemia, n (\%) & 146(39.9) & 143(39.1) & 0.44 \\
\hline Preoperative ALB(g/L), mean $\pm S D$ & $39.83 \pm 4.26$ & $40.63 \pm 4.96$ & 0.18 \\
\hline Preoperative $\mathrm{CRP}(\mathrm{g} / \mathrm{L})$, mean $\pm \mathrm{SD}$ & $11.87 \pm 3.16$ & $12.04 \pm 3.88$ & 0.35 \\
\hline Preoperative WBC (109/L), mean \pm SD & $8.01 \pm 2.62$ & $8.14 \pm 2.69$ & 0.39 \\
\hline \multicolumn{4}{|l|}{ Ultrasound presentation } \\
\hline Mean $\mathrm{CBD}(\mathrm{cm})$, mean $\pm \mathrm{SD}$ & $1.75 \pm 0.53$ & $2.07 \pm 0.86$ & 0.18 \\
\hline Nadir ALB within POD $2(\mathrm{~g} / \mathrm{L})$, mean $\pm \mathrm{SD}$ & $33.13 \pm 8.56$ & $32.34 \pm 7.69$ & 0.23 \\
\hline Postoperative WBC (109/L), mean \pm SD & $15.56 \pm 4.64$ & $15.12 \pm 4.63$ & 0.46 \\
\hline \multicolumn{4}{|l|}{ Mode of surgical approach, $n(\%)$} \\
\hline Laparoscopic & $131(35.8)$ & $126(34.4)$ & \\
\hline Open & $235(64.2)$ & $240(65.6)$ & 0.38 \\
\hline Nadir of hemoglobin(g/L) & $9.35 \pm 1.25$ & $9.48 \pm 1.52$ & 0.33 \\
\hline Operative blood loss (mL) & $35.16 \pm 14.69$ & $34.47 \pm 13.53$ & 0.29 \\
\hline Intraoperative fluid utilization $(\mathrm{mL} / \mathrm{kg} * \mathrm{~h})$, mean $\pm \mathrm{SD}$ & $15.59 \pm 6.54$ & $14.93 \pm 6.18$ & 0.27 \\
\hline Intraoperative transfusion, $\mathrm{n}(\%)$ & $102(27.9)$ & $98(26.8)$ & 0.40 \\
\hline \multicolumn{4}{|l|}{ ASA classification } \\
\hline ASA 1-2 & $262(71.6)$ & $257(70.2)$ & 0.37 \\
\hline ASA3-4 & $104(28.4)$ & $109(29.8)$ & \\
\hline
\end{tabular}

Table 4. Outcome characteristics in the matched population depended on the mean value of $\triangle A L B$ 


\begin{tabular}{|c|c|c|c|c|}
\hline & $\Delta \mathrm{ALB}>14.6 \%(366)$ & $\Delta \mathrm{ALB}<14.6 \%(366)$ & p Values & Odds ratio $(95 \% \mathrm{Cl})$ \\
\hline Hypoten sive events, n(\%) & 42(10.47) & $38(11.88)$ & 0.36 & \\
\hline Norepinephrine usage, n(\%) & $45(13.95)$ & $40(12.17)$ & 0.32 & \\
\hline Furosemidum, n(\%) & $36(9.88)$ & $34(11.30)$ & 0.50 & \\
\hline Metabolic acidosis, n(\%) & 18(3.20) & $13(4.93)$ & 0.23 & \\
\hline hypokalemic episodes, n(\%) & 24 & 25 & 0.50 & \\
\hline \multicolumn{5}{|l|}{ Serum albumin } \\
\hline First defecation (days) & $3.13 \pm 1.32$ & $2.88 \pm 1.27$ & 0.12 & \\
\hline First flatus & $3.56 \pm 0.88$ & $3.07 \pm 0.90$ & 0.013 & \\
\hline First bowel movement(days), Mean \pm SD & $2.75 \pm 0.82$ & $2.14 \pm 0.78$ & 0.019 & \\
\hline Stool with in 72 hours, $n$ (\%) & 123(32.75) & 147(40.12) & 0.039 & $1.33(0.98-1.79)$ \\
\hline Abdominal distension, $\mathrm{n}(\%)$ & $36(13.5)$ & $28(19.8)$ & 0.18 & \\
\hline Diarrhea, n (\%) & $23(6.8)$ & 21(10.9) & 0.50 & \\
\hline Vomiting, n (\%) & $35(13.0)$ & $31(16.1)$ & 0.38 & \\
\hline No. of patients with mild complications, n(\%) & $45(11.7)$ & $29(9.0)$ & 0.033 & $1.63(1.00-2.66)$ \\
\hline No. of patients with major complications, $n(\%)$ & $28(7.7)$ & 21 & 0.19 & \\
\hline Total number of complications, $\mathrm{n}(\%)$ & $59(16.1)$ & $40(10.9)$ & 0.026 & $1.57(1.02-2.41)$ \\
\hline Length of stay $(d)$, mean $\pm S D$ & $8.19 \pm 3.16$ & $7.69 \pm 2.67$ & 0.057 & \\
\hline
\end{tabular}

